This article was downloaded by: [Queen Margaret University]

On: 6 October 2009

Access details: Access Details: [subscription number 906453358]

Publisher Psychology Press

Informa Ltd Registered in England and Wales Registered Number: 1072954 Registered office: Mortimer House, 37-41 Mortimer Street, London W1T 3JH, UK
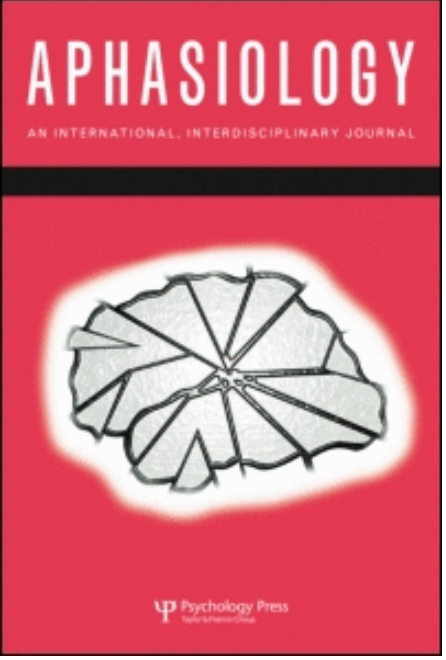

\title{
Aphasiology
}

Publication details, including instructions for authors and subscription information:

http://www.informaworld.com/smpp/title content=t713393920

\section{The incidence of cases of aphasia following first stroke referred to speech and language therapy services in Scotland}

James Law a; Robert Rush a; Ann-Marie Pringle b; Anne-Marie Irving c; Guro Huby d; Mark Smith b; Douglas Conochie a; Catherine Haworth a; Amanda Burston ${ }^{\mathrm{e}}$

${ }^{a}$ Queen Margaret University, Edinburgh, Scotland, UK ${ }^{b}$ NHS Lothian, Scotland, UK ${ }^{c}$ NHS Forth Valley,

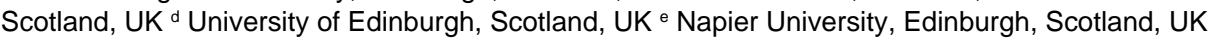

First Published on: 13 February 2009

To cite this Article Law, James, Rush, Robert, Pringle, Ann-Marie, Irving, Anne-Marie, Huby, Guro, Smith, Mark, Conochie, Douglas, Haworth, Catherine and Burston, Amanda(2009)'The incidence of cases of aphasia following first stroke referred to speech and language therapy services in Scotland',Aphasiology,23:10,1266 - 1275

To link to this Article: DOI: 10.1080/02687030802514953

URL: http://dx.doi.org/10.1080/02687030802514953

\section{PLEASE SCROLL DOWN FOR ARTICLE}

Full terms and conditions of use: http://www.informaworld.com/terms-and-conditions-of-access.pdf

This article may be used for research, teaching and private study purposes. Any substantial or systematic reproduction, re-distribution, re-selling, loan or sub-licensing, systematic supply or distribution in any form to anyone is expressly forbidden.

The publisher does not give any warranty express or implied or make any representation that the contents will be complete or accurate or up to date. The accuracy of any instructions, formulae and drug doses should be independently verified with primary sources. The publisher shall not be liable for any loss, actions, claims, proceedings, demand or costs or damages whatsoever or howsoever caused arising directly or indirectly in connection with or arising out of the use of this material. 


\title{
Research Note
}

\section{The incidence of cases of aphasia following first stroke referred to speech and language therapy services in Scotland}

\author{
James Law and Robert Rush \\ Queen Margaret University, Edinburgh, Scotland, UK \\ Ann-Marie Pringle \\ NHS Lothian, Scotland, UK \\ Anne-Marie Irving \\ NHS Forth Valley, Scotland, UK \\ Guro Huby \\ University of Edinburgh, Scotland, UK \\ Mark Smith \\ NHS Lothian, Scotland, UK \\ Douglas Conochie and Catherine Haworth \\ Queen Margaret University, Edinburgh, Scotland, UK \\ Amanda Burston \\ Napier University, Edinburgh, Scotland, UK
}

\begin{abstract}
Background: Key to the provision of appropriate services is an understanding of the number of cases in a given population. This study examined the incidence of aphasia following first ever stroke. It was part of a larger study, the Aphasia in Scotland Study, which examined the provision of services for people with aphasia in Scotland.

Aims: The present study examines the incidence of aphasia referred to speech and language therapy services in people who have experienced their first ever stroke. The specific questions addressed were: What is the incidence of aphasia following first ever stroke? What is the percentage of aphasia following first ever stroke? What are the crude figures for aphasia following first ever stroke by age? What are the crude figures for aphasia following first ever stroke by gender? What are the crude figures for aphasia following first ever stroke by severity?

Methods \& Procedures: All 14 health boards in Scotland were approached but only 3, NHS Borders, Orkney, and Shetland, were able to provide the level of information
\end{abstract}

\footnotetext{
Address correspondence to: Professor James Law, Centre for Integrated Healthcare Research, Queen Margaret University, Edinburgh EH216UU, UK. E-mail: jlaw@qmu.ac.uk

(C) 2009 Psychology Press, an imprint of the Taylor \& Francis Group, an Informa business http://www.psypress.com/aphasiology 
required. Respondents were asked to provide information about the age and gender and level of communication need of referred cases over a given year.

Outcomes \& Results: Results suggested that the incidence of aphasia following first ever stroke was found to be 54, 57, and 77.5 per 100,000, for NHS Borders, Orkney, and Shetland respectively. This is slightly higher than in other comparable studies. The percentage of new cases of aphasia following a first ever stroke across NHS Borders, Orkney, and Shetland was 19,22, and 34\% respectively. The variability across the three sites is probably a function of the potential effect of small changes in the relatively low numbers. The majority of cases were, unsurprisingly, over 65 years of age but a substantial minority-17\% (Shetland), 26\% (Borders) and 36\% (Orkney) - were below 65 years of age. One third of new cases resulted in severe aphasia. Although the proportions of men and women with aphasia were similar, women tended to be older at the point at which they experienced their first stroke.

Conclusions: The results are discussed in terms the practicalities of this sort of data collection exercise and the implications of the results for service delivery. There is a need for comparable local data collection exercises tied in to current epidemiological studies.

Keywords: Stroke; Aphasia; Incidence.

There is considerable variability in reporting the incidence of aphasia following stroke. There are number of reasons for this, including the derivation of the data (clinical versus normal populations), the definitions used, and the timing of the assessments post stroke. The most recent population study in the field used multiple data sources give a figure of 43 in 100,000 inhabitants with aphasia resulting from first ischaemic stroke (Engelter et al., 2006). Advancing age and cardio-embolism were associated with an increased risk for aphasia. The point post stroke at which the data are collected is also important. The proportion of clinical cases of aphasia post stroke varies considerably. Thus $55 \%$ of a sample of consecutively referred patients examined 15-30 days post stroke were found to be aphasic (Scarpa, Colombo, Sorgato, De Renzi 1987). But presence of aphasia is also a function of the time post stroke. Thus, in another study, the figure dropped from $38 \%$ at the time of admission to hospital to $18 \%$ at discharge (Pedersen, Jorgensen, Nakayama, Raaschou, \& Olsen 1995). In this study sex, handedness, and site of stroke lesion had very little effect on outcome and the influence of age was minimal. By contrast, in a study following patients over an 18-month period post stroke $43 \%$ were found to still have aphasia 18 months after stroke onset, with a proportion of global and Wernicke's aphasia decreasing and a corresponding increase in conduction aphasia (Laska, Hellblom, Murray, Kahan, \& Von Arbin 2001). In the same study greatest improvements were noted for those who were younger and those with mild aphasia and with speech difficulties. Clearly from the point of view of developing appropriate services, there is a need to examine the number of confirmed cases, i.e., cases where the aphasia is persistent, rather than focusing on those for whom the aphasia is transient.

The present study examined referral rates of aphasia first stroke to speech and language therapy departments. It was part of a larger study to describe speech and language therapy services for people with aphasia following stroke in Scotland (Law et al., 2007).

The specific research questions were:

- What is the incidence of aphasia following first ever stroke?

- What is the percentage of aphasia following first ever stroke? 
- What are the crude figures for aphasia following first ever stroke by age?

- What are the crude figures for aphasia following first ever stroke by gender?

- What are the crude figures for aphasia following first ever stroke by severity?

\section{METHOD}

The speech and language therapy departments in all 14 health boards in Scotland were asked to provide data on referrals to their services over the course of a 12-month period during 2004 to 2005. In the event, three health boards, NHS Borders, Orkney, and Shetland, were able to collect data. In the other areas, although it was often technically possible to collect information in all areas except severity, data collection was hampered by the resource challenges associated with manual data collection for the speech and language therapy departments concerned.

The age of the individual patients was calculated at their first contact with the speech and language therapy services. Severity of aphasia was rated by a speech and language therapist using the Communication Severity Rating Scale, first developed as the Aphasia Severity Rating Scale by Goodglass and colleagues (Goodglass, Kaplan \& Barresi, 2001; see Table 5 below). This scale is used in clinical practice and was adopted for the purposes of this study. It was applied by a representative of the speech and language therapy services at the point at which the data were collected for the present study and applied to the level of difficulty experienced at the point that individual was referred to the speech and language therapy services. The Communication Severity Rating Scale incorporates both expressive language difficulties and comprehension difficulties. It is not a measure of the impact of aphasia or the level of an individual's need more broadly, but it does highlight the level of involvement of the conversational partner, something that is rarely included in formal assessments but is critical to understanding the level of support required.

To arrive at an accurate age- and gender-specific incidence estimate for stroke for the Scottish Health Boards we required an accurate initial crude estimate for ageand gender-specific stroke incidence on which to base our figures. We used the Scottish Borders Stroke Study (SBSS) (Syme, Byrne, Chen, Devenny, \& Forbes 2005) crude age-specific incidence figure and the method of direct standardisation to account for differences in age and sex in the Health Board mid-2002 population structures. There are a number of weaknesses in using the direct standardisation. For example, the rates may not be stable for a small number of events (approximately $<100)$ and Confidence Intervals for age-standardised rates are unreliable where there are fewer than 50 cases in an area. This is because the formula commonly used is a simplified version and assumes a normal distribution.

The recent Scottish Borders Stroke Study (SBSS) provided a sound incidence estimate that met all the criteria required for an "ideal" community-based incidence study in stroke (Malmgren, Warlow, Bamford, \& Sandercock 1987). The SBSS used as its definition of stroke that of the World Health Organisation (WHO), to give us a gender- and age-specific estimate of the incidence of first-ever-in-a-lifetime stroke (FES) and transient ischaemic attack (TIA), within the Borders region, and allowed us to apply this to the mid-2002 age- and gender-specific populations for our three Scottish health board regions of interest. In addition, this study validated all suspected stroke and TIA patients, most within 48 hours of their event. The Borders study was contemporary and carried out on a Scottish population, being gathered 
over a 24-month period from 1998 to 2000. To endeavour to capture "all" stroke cases it is imperative to obtain complete case ascertainment of all stroke events to ensure that incidence rates are accurate, and multiple overlapping techniques and hot pursuit achieved this. The SBSS used multiple overlapping methods to maximise case ascertainment (involving general practitioners, hospital nursing staff, neurovascular clinic staff, social services, and Chest Heart and Stroke Scotland). The population in this study was also suited to an epidemiological study because it was extremely stable and was served by one main hospital. In terms of the quality of the stroke register data, all the key quality indicators recommended by the WHO Monitoring Trends and Determinants in Cardiovascular Disease committee were met, allowing multinational comparison.

The SBSS team acknowledge that the crude incidence rate is one of the highest in the world, but age-adjusted rates, case fatality, and relative risk for all stroke were not significantly different from the majority of previous studies. The Scottish risk of stroke would appear to be similar to, if a little higher than, other populations worldwide with any differences in crude incidence most likely to be attributable to the differences in the proportion of elderly across studies, (percentage of the population $>=65$ years of age was $18.8 \%$; the Scottish average is $16 \%$ ) and not differences in vascular risk.

\section{RESULTS}

\section{What is the incidence of aphasia following first stroke?}

Table 1 shows the number of cases of aphasia following first ever stroke within the three health board areas. Incidence of aphasia following first ever stroke has then been calculated from estimates of health board area populations. The data collected indicates that the incidence of aphasia following first ever stroke in NHS Borders, Orkney, and Shetland was 54,57 , and 77.5 per 100,000 respectively.

These figures are rather higher than the figure of 43 in 100,000 reported in the recent study in Basel, Switzerland (Engelter et al., 2006). It is possible that the differences may be accounted for by the way in which the data were collected in this study.

\section{What is the percentage of aphasia following first ever stroke?}

These rates of aphasia incidence can be compared to rates of incidence for first ever stroke and an estimated percentage of aphasia following first ever stroke can be

TABLE 1

Incidence of aphasia following first ever stroke across three health boards

\begin{tabular}{lccc}
\hline Health board Year & $\begin{array}{c}\text { Number of cases of } \\
\text { aphasia following } \\
\text { first ever stroke }\end{array}$ & $\begin{array}{c}\text { Estimated population } \\
\text { of health board }\end{array}$ & $\begin{array}{c}\text { Aphasia incidence } \\
\text { following first ever } \\
\text { stroke }\end{array}$ \\
\hline NHS Borders Oct 2005-Sep 2006 & 58 & 107,400 & 54 per 100,00 \\
NHS Orkney Oct 2004-Sep 2005 & 11 & 19,210 & 57 per 100,000 \\
NHS Shetland Oct 2004-Sep 2005 & 17 & 21,940 & 77.5 per 100,000 \\
\hline
\end{tabular}

\footnotetext{
*General Register Office for Scotland (2002).
} 
TABLE 2

Estimated percentage of aphasia resulting from first ever stroke across three health boards

\begin{tabular}{lccc}
\hline Health board & $\begin{array}{c}\text { Estimated first ever } \\
\text { stroke per 100,000* }\end{array}$ & $\begin{array}{c}\text { Aphasia following first } \\
\text { ever stroke per 100,000 }\end{array}$ & $\begin{array}{c}\text { Estimated percentage of aphasia } \\
\text { following first ever stroke }\end{array}$ \\
\hline NHS Borders & 284 & 54 & $19 \%$ \\
NHS Orkney & 262 & 57 & $22 \%$ \\
NHS Shetland & 227 & 77.5 & $34 \%$ \\
\hline
\end{tabular}

*Extracted from Syme et al., 2005.

calculated. Table 2 indicates that approximately $19 \%, 22 \%$, and $34 \%$ of people in NHS Borders, Orkney, and Shetland had aphasia after their first ever stroke.

Again the figures would appear to be rather higher than some of the most recent estimates of aphasia following first stroke provided from the Oxfordshire Community Stroke project, whose authors cite $19 \%$ based on an assessment by a neurologist (Aerden et al., 2004; Dennis, personal communication 2007). But they are comparable to others that have had a wider remit. In part this may be a function of the point at which the data were collected. As indicated above, all those with aphasia in the present study had been referred and seen by speech and language therapists and would fall within this range. This raises an issue, which is not the subject of the present report, namely the role of providing early acute sector interventions that have the potential to have a significant effect on the prevalence and severity of aphasia.

\section{What are the crude figures for aphasia following first ever stroke by age?}

Table 3 shows crude values for the age of people with new cases of aphasia following first ever stroke for the three health boards. This information is shown within four age brackets. This table shows the majority of people who have aphasia following first ever stroke to be over 65, although 17.6\% (Shetland), 26\% (Borders), and 36.4\% (Orkney) of people who have aphasia following first ever stroke were found to be under 65 .

TABLE 3

Number of new cases of aphasia following first ever stroke across three health boards in four age brackets

\begin{tabular}{lcccc}
\hline & $0-24$ & $25-44$ & $45-64$ & $65+$ \\
\hline $\begin{array}{l}\text { NHS Borders } \\
\text { (58 cases) }\end{array}$ & 0 & 4 & 11 & 43 \\
NHS Orkney & & $(7 \%)$ & $(19 \%)$ & $(74 \%)$ \\
$(11$ cases $)$ & 0 & 0 & $(36.4 \%)$ & 7 \\
NHS Shetland & 0 & 0 & 3 & $(63.6 \%)$ \\
$(17$ cases $)$ & & & $(17.6 \%)$ & 14 \\
\hline
\end{tabular}


TABLE 4

Number of new cases of aphasia following first ever stroke across three health boards by gender

\begin{tabular}{lccc}
\hline & \multicolumn{3}{c}{ Gender } \\
Health board & Male & Female & Total \\
\cline { 2 - 4 } NHS Borders & 26 & 32 & 58 \\
NHS Orkney & $(44.8 \%)$ & $(55.2 \%)$ & $(100 \%)$ \\
NHS Shetland & 6 & 5 & 11 \\
& $(54.5 \%)$ & $(45.5 \%)$ & $(100 \%)$ \\
& 9 & 8 & 17 \\
& $(52.9 \%)$ & $(47.1 \%)$ & $(100 \%)$ \\
\hline
\end{tabular}

\section{What are the crude figures for aphasia following first ever stroke by gender?}

Table 4 shows crude values for the gender of people with new cases of aphasia following stroke for the three health boards. This table shows a fairly equal division between men and women who have aphasia following first ever stroke in the three health boards. If the gender data are then cross-tabulated against age we find that, although the proportions across genders are comparable, women tend to become aphasic at an older age than men.

\section{What are the crude figures for aphasia following first ever stroke by severity?}

Table 5 shows crude values for the severity of new cases of aphasia following first ever stroke for the three health boards. The Communication Severity Rating Scale has six ordered categories: 0 represents the most severe communication difficulty and 5 represents "minimal" difficulties which may not be apparent to the lay person. The full Communication Severity Rating Scale can be seen in Table 5.

TABLE 5

Communication Severity Rating Scale

\begin{tabular}{ll}
\hline Score & \multicolumn{1}{c}{ Description of behaviour } \\
\hline 0 & $\begin{array}{l}\text { No usable speech or auditory comprehension } \\
\text { All communication is through fragmentary expression; great need for inference, questioning, } \\
\text { and guessing by the listener. Range of information that can be exchanged is limited, and the } \\
\text { listener carries the burden of communication }\end{array}$ \\
& $\begin{array}{l}\text { Conversation about familiar subjects is possible with help from the listener. There are frequent } \\
\text { failures to convey the idea, but patient shares the onus of communication with the examiner }\end{array}$ \\
& $\begin{array}{l}\text { The patient can discuss almost all everyday problems with little or no assistance. However, } \\
\text { reduction of speech and/or comprehension make conversation about certain material difficult } \\
\text { or impossible } \\
\text { Some obvious loss of fluency in speech or facility of comprehension, without significant } \\
\text { limitation on ideas expressed or form of expression } \\
\text { Minimal discernible speech handicaps: Patient may have subjective difficulties that are not } \\
\text { apparent to listener }\end{array}$ \\
\hline
\end{tabular}

Adapted from: Goodglass, H., Kaplan, E., and Barresi, B. (2001). The assessment of aphasia and related disorders, third edition. Baltimore: Lippincott, Williams \& Wilkins. 
TABLE 6

Number of new cases of aphasia following first ever stroke across three health boards for six different severity ratings

\begin{tabular}{|c|c|c|c|c|c|c|c|}
\hline & \multicolumn{6}{|c|}{ No usable speech $\rightarrow$ Minimal difficulties } & \multirow{2}{*}{$\begin{array}{l}\text { No data } \\
\text { available }\end{array}$} \\
\hline & 0 & 1 & 2 & 3 & 4 & 5 & \\
\hline \multicolumn{8}{|l|}{$N H S$} \\
\hline $\begin{array}{l}\text { Borders } \\
\text { (58 cases) } \\
N H S\end{array}$ & $\begin{array}{c}8 \\
(13.8 \%)\end{array}$ & $\begin{array}{c}14 \\
(24.1 \%)\end{array}$ & $\begin{array}{c}5 \\
(8.6 \%)\end{array}$ & $\begin{array}{c}3 \\
(5.2 \%)\end{array}$ & $\begin{array}{c}12 \\
(20.7 \%)\end{array}$ & $\begin{array}{c}4 \\
(6.9 \%)\end{array}$ & $\begin{array}{c}12 \\
(20.7 \%)\end{array}$ \\
\hline $\begin{array}{l}\text { Orkney } \\
\text { (11 cases) } \\
N H S\end{array}$ & $\begin{array}{c}1 \\
(9.1 \%)\end{array}$ & $\begin{array}{c}3 \\
(27.3 \%)\end{array}$ & $\begin{array}{c}3 \\
(27.3 \%)\end{array}$ & $\begin{array}{c}1 \\
(9.1 \%)\end{array}$ & 0 & $\begin{array}{c}3 \\
(27.3 \%)\end{array}$ & 0 \\
\hline $\begin{array}{l}\text { Shetland } \\
\text { (17 cases) }\end{array}$ & 0 & $\begin{array}{c}3 \\
(17.6 \%)\end{array}$ & $\begin{array}{c}9 \\
(53 \%)\end{array}$ & 0 & $\begin{array}{c}3 \\
(17.6 \%)\end{array}$ & $\begin{array}{c}2 \\
(11.8 \%)\end{array}$ & 0 \\
\hline
\end{tabular}

Table 6 shows that approximately one third of cases were within the two most severe categories - i.e., with little or no usable speech - although this was not true for one health board (Shetland) again suggesting that caution needs to be applied to the interpretation of relatively small numbers.

\section{DISCUSSION AND CONCLUSIONS}

The incidence of aphasia following first ever stroke was found to be 54, 57, and 77.5 per 100,000 in the three sampled health boards, NHS Borders, Orkney, and Shetland. The percentage of new cases of aphasia following a first ever stroke in NHS Borders, Orkney, and Shetland was $19 \%, 22 \%$, and $34 \%$ respectively. This is rather higher than in other studies, although this may be explained in part by the slightly older populations in the responding health boards, but it is important to note there is also a relatively high proportion of cases in the under 65 age group $-17 \%$ (Shetland), 26\% (Borders), and 36\% (Orkney). One third of new cases result in severe aphasia, suggesting that the relationship between severity and age is not simple. There was a comparable level of aphasia following stroke for men and women although the women tended to be in the older age groups.

\section{Caveats}

The data reported here came from authorities that were able to go back over their records and extract data for this project. It is important that they reflect both aphasia following first ever stroke and those with aphasia who are referred to speech and language therapy services. It is also important to note that these figures are not a representation of the total incidence of aphasia. There are no obvious demographic reasons for the different rates across health boards and this is probably a function of the substantial effect of small changes in the relatively low numbers. Similarly they do not include those who present in primary care but who do not get referred on to acute services or to speech and language therapy directly. They also do not include aphasia from other aetiologies, i.e., those not caused by stroke. Given these provisos, it is perhaps surprisingly that the figures are rather higher than other estimates. They suggest either that there are relatively few cases that are missed by the services, and 
that there is not therefore a pool of unmet need or, if there is, that the true numbers are higher still. Given that we tied our data back to the Scottish Borders Stroke Study data, it would be reasonable to assume that the former is more likely than the latter. It is also important to acknowledge that our data refer to the number of cases rather than the true impact of the aphasia on the lives of the individuals concerned and the corresponding level of need. Finally, it is worth commenting on the application of the Communication Severity Rating Scale. The intention was to capture the level of difficulty at the point that the individuals were registered with speech and language therapy services. It is, of course, possible that the severity of their aphasia may have subsequently reduced either spontaneously or as a result of the therapy that they received. Eliciting this information was not a feature of this study but should be considered in the development of further studies.

\section{Centralised collection of data}

There is no routine data collected related to aphasia related to stroke in Scotland. Currently the only way of collecting data addressing critical service-level issues such as age and severity is through the willingness of local services to hand-search their records. This is a relatively inefficient way of addressing data collection and makes it virtually impossible to plan services for this client group. Given the priority attributed to stroke in the development of health and social services in Scotland, and given the relatively high proportion of people who have moderate to severe aphasia following first stroke, a figure that will necessarily increase as second and later strokes are added in, this issue should be considered a priority. Data on incidence of aphasia following stroke are not routinely collected in Scotland, although this issue is currently under review. For example, the minimal dataset recommended by Dennis (2006) for hospital-based stroke services included a question on whether the patient can talk. Similarly there are moves to include aphasia on the National Clinical Dataset http://www.sehd.scot.nhs.uk/ahpechip/ docs/NationalClinicalDatasetDevProg.pdf. In neither case is there a clear recommendation that data be collected on severity and impact of aphasia. We would consider that subject to reliability there is a case for adopting a version of the Communication Severity Rating Scale to address this issue.

Data collection is also an issue when it comes to the identification of the symptomatology of aphasia. It would be very helpful to supplement the acute sector data with information about the number of people with aphasia with chronic aphasia presenting in their general practitioners' surgeries. As a part of this study, and in analyses presented elsewhere (Law et al., 2009), we sought the opinion of people with aphasia about the knowledge of health professionals about aphasia. These opinions were elicited through focus groups and through an "Experienced Service User Group" set up for the purposes of the project, Broadly our informants told us that they experienced a distinct lack of awareness of the nature of the presenting symptoms of aphasia among non-specialist medical and healthcare staff. This knowledge gap would suggest two specific modifications to existing service delivery. In the first instance there would need to be training for GPs in the identification of the symptoms of aphasia, and second there needs to be a way that GPs can flag up aphasia on their computerised systems. Obviously the two would be closely related. 
Identifying the level of severity of need is more complex than it would first appear. A number of different ways are available for doing this, using standardised tests, rating scales, or eliciting the impact of their experience from the individual themselves. While it is relatively simple to objectify severity in terms of an individual's performance on a test of language ability, it is much less clear how this relates to that individual's pre-morbid communication ability. Level of tested difficulty does not necessarily map onto need. It was clear, from both our focus groups and from the involvement of our Experienced Service User's Group, that severity does not necessarily reflect the impact that aphasia can have on an individual's life. A relatively mild aphasia can have a devastating effect on the performance of some individuals making it difficult to hold down a job, drive a car, etc. The Communication Severity Rating Scale goes some way to addressing this issue, in so far as it acknowledges the level of dependency of the person with aphasia on their interlocutor. But this type of measure inevitably includes an interpretative element and is likely to be more difficult to apply with high levels of reliability, something that was not tested in the present study. Indeed the greater the emphasis on impact and the subjective experience of the individual with aphasia, the more challenging the whole concept of the level of need in a population becomes. It is obviously much more difficult to calculate the incidence of an impact perceived by the person with the stroke than it is to impose some externally defined objective criterion such as a cut-point on a norm-referenced test.

The age at which people experience their first stroke is also an important issue when it comes to planning services. It is commonly assumed that stroke is a phenomenon confined to the elderly. The data collected in the present study suggest that this is not the case, with as many as a third of patients being below the age of retirement. This is likely to affect the nature of the concerns (getting back into work, managing family commitments etc.) that will be important to those concerned. This issue came up in our subsequent questionnaire to practitioners as part of the same study (Law et al., 2007) and it is clearly not a simple matter of treating people differently when they pass the retirement watershed. Speech and language therapists commonly indicated that their approach to therapy was more likely to reflect lifestyle, motivation, and the severity of the aphasia than age as such. Again it is difficult to match the needs of different groups to the services provided without robust data.

\section{CONCLUSIONS}

Good data collection is key to the equitable delivery of services in any area. Servicelevel data of the type collected in this study maps reasonably well onto existing incidence data, although this is sensitive to a number of critical factors such as the timing of the assessment and the level of need identified. That said, the data do show that while there is considerable variation on the profile from one health board to another, there is a need for the collection of local data on the level of communication dependence of people with aphasia and the matching of that information to service provision. 


\section{REFERENCES}

Aerden, L., Luijckx, G. J., Ricci, S., Hilton, A., Kessels, F., \& Lodder, J. (2004). Validation of the Oxfordshire Community Stroke Project syndrome diagnosis derived from a standard symptom list in acute stroke. Journal of the Neurological Sciences, 220, 55-58.

Dennis, M. (2006). Developing a national system to monitor the quality of hospital-based stroke services. Edinburgh, UK: NHS Quality Improvement, Scotland.

Dennis, M. (2007) [Unpublished data from the Oxfordshire Community Stroke Project.] Personal communication.

Engelter, S. T., Gostynski, M., Papa, S., Frei, M., Born, C., \& Ajadacic-Gross, V. et al. (2006). Epidemiology of aphasia attributable to first ischaemic stroke: Incidence, severity, fluency, etiology and thrombolysis. Stroke, 37, 1379-1384.

General Register Office for Scotland. (2002). Estimated population by sex, single year of age and administrative area. Retrieved April 25, 2006, from: http://www.groscotland.gov.uk/statistics/ publications-and-data/population-estimates/02-mid-year-tables/index.html.

Goodglass, H., Kaplan, E., \& Barresi, B. (2001). The assessment of aphasia and related disorders, 3rd edition. Baltimore: Lippincott, Williams \& Wilkins.

Laska, A. C., Hellblom, A., Murray, V., Kahan, T., \& Von Arbin, M. (2001). Aphasia in acute stroke and relation to outcome. Journal of Internal Medicine, 249(5), 413-422.

Law, J., Irving, A-M., Huby, G., Pringle, A-M., Smith, M., \& Conochie, D. et al. (2009). Reconciling the perspective of practitioner and service user: Findings from the Aphasia in Scotland Study. Manuscript in preparation.

Law, J., Rush, R., Pringle, A., Irving, A., Huby, G., \& Smith, M. et al. (2007). Aphasia in Scotland. Edinburgh, UK: NHS Quality Improvement Scotland.

Malmgren, R., Warlow, C., Bamford, J., \& Sandercock, P. (1987). Geographical and secular trends in stroke incidence. Lancet, 2, 1196-1200.

Pedersen, P. M., Jorgensen, H. S., Nakayama, H., Raaschou, H. O., \& Plsen, T. S. (1995). Aphasia in acute stroke: Incidence, determinants and recovery. Annals of Neurology, 38, 659-666.

Scarpa, M., Colombo, A., Sorgato, P., \& De Renzi, E. (1987). The incidence of aphasia and global aphasia in left brain-damaged patients. Cortex, 23(2), 331-336.

Syme, P. D., Byrne, A. W., Chen, R., Devenny, R., \& Forbes, J. F. (2005). Community- based stroke incidence in a Scottish population: The Scottish Borders Stroke Study. Stroke, 36, 1837-1843. 